\title{
Maternal provisioning gives young-of-the-year Hammerheads a head start in early life
}

\author{
Kady Lyons ${ }^{1,6}$ (1) - Ashley S. Galloway ${ }^{2}$ - Douglas H. Adams ${ }^{3}$ (D) - Eric A. Reyier ${ }^{4}$ - Amanda M. Barker ${ }^{5}$. \\ David S. Portnoy ${ }^{5}$ Bryan S. Frazier ${ }^{2}$
}

Received: 3 July 2020 / Accepted: 9 September 2020 / Published online: 6 October 2020

(c) The Author(s) 2020

\begin{abstract}
For species that do not provide parental care after birth, excess maternal provisioning during development, beyond what is required for embryogenesis, provides offspring with resources to increase their chances of survival. Maternally derived resources are expected to be important for buffering offspring against limited food resources at birth or time needed to learn how to properly feed. Young-of-the-year (YOY) cryptic Scalloped Hammerheads (Sphyrna lewini) and Carolina Hammerheads (Sphyrna gilberti) were sampled from nurseries along the US Atlantic Coast and compared for a number of biological condition metrics across three developmental stages. Large declines in liver lipid content and hepatosomatic indices were found in neonatal sharks, using umbilical scar healing as a proxy for time since birth. Feeding commenced quickly as $96 \%$ of sharks had prey remnants in their stomachs. The combination of rapid exhaustion of maternally provided resources and high occurrence of stomachs with prey contents indicate that nursery quality, with respect to prey availability, may be important for YOY hammerhead survivorship. While externally the two species are morphologically similar, longer length-at-birth in S. lewini and higher hepatic condition in neonatal S. gilberti suggest that aspects of reproductive biology, including physiology, may differ between species. While more information is needed to distinguish life history differences between these two species, data collected from YOY may serve as a useful proxy to inform management when adult samples of cryptic species are difficult to collect.
\end{abstract}

Responsible Editor: J. Carlson.

Reviewed by undisclosed experts.

Electronic supplementary material The online version of this article (https://doi.org/10.1007/s00227-020-03766-y) contains supplementary material, which is available to authorized users.

Kady Lyons

kady.lyons@sbcglobal.net

1 Department of Biological Sciences, California State University Long Beach, Long Beach, CA, USA

2 South Carolina Department of Natural Resources, Charleston, SC, USA

3 Florida Fish and Wildlife Conservation Commission, Fish and Wildlife Research Institute, Melbourne, FL, USA

4 Kennedy Space Center Ecological Program and Integrated Mission Support Services, Kennedy Space Center, FL, USA

5 Department of Life Sciences, Texas A\&M University-Corpus Christi, Corpus Christi, TX, USA

6 Georgia Aquarium, Atlanta, GA, USA

\section{Introduction}

Female elasmobranchs (sharks, skates, and rays) invest heavily in reproduction, employing a gamut of energetic investment strategies to provision their young during development (e.g., egg laying to pseudoplacental; Cotton et al. 2015; Musick and Ellis 2005). Approximately 30\% of elasmobranch species are viviparous providing some form of matrotrophy (supplemental provisioning by mothers) during gestation (Compagno 1990; Hamlett, Kormanik et al. $2005 \mathrm{a}, \mathrm{b}$ ). The development of a placental structure in both viviparous elasmobranchs (an ancient taxa) and mammals (an evolutionarily younger taxa) is the result of evolutionary convergence upon a highly derived form of maternal-embryo connection. The structure of an elasmobranch placenta is physiologically distinct from that of mammals with varying degrees of maternal-embryo interfacing. The form of placentotrophy used by most sharks is the yolk-sac placenta, where the embryonic yolk sac is modified during development forming a connection to the uterine wall with subsequent formation of an umbilical stalk (Wourms et al. 1988) 
through which embryos receive nutrients from their mother. Prior to establishment of this connection, embryos primarily rely on energy stores found in their external yolk sacs, supplied by their mothers prior to ovulation (Hamlett, Jones et al. 2005a, b). Thus, embryos are provided with maternally derived nutrients from the beginning to end of development, enabling females two pathways to transfer substantial resources to young.

Since maternal care after birth in elasmobranchs is absent, a female's only opportunity to invest resources directly into young occurs during egg production or pregnancy. Elasmobranchs are fully formed at parturition and are technically capable of feeding upon birth, in that they possess the needed mechanical components of prey capture (e.g., jaws, teeth, musculature). However, feeding may be limited immediately after birth, as was observed for Dusky Sharks (Carcharhinus obscurus) where neonates with more open scars had lower stomach content masses than those with more healed scars (Hussey et al. 2010). The ability of newborn sharks to feed could be temporally constrained for a number of reasons. For example, it may take time to learn proper feeding behavior (Lowe 2002; Guttridge et al. 2009), environmental resources could be reduced or absent (Bush 2003), or they may be born in localities with limiting resources necessitating migration to resource rich areas (Ulrich et al. 2007). Regardless of the reasons, during this critical period young sharks are expected to rely heavily on maternal resources received in utero. Therefore, maternal investment in young may be critical for offspring survival, giving neonates a "head start" or "buffer" between birth and the time it takes to feed effectively (Congdon 1989; Hussey et al. 2010). It follows that the more nutritional reserves embryos receive prior to birth, the longer neonates may be able to delay exogenous feeding (i.e., acquisition of their own resources). While many elasmobranch species use nursery areas, nurseries are not always rich in food resources, and may function to provide other benefits such as protection from predators (Castro 1993; Simpfendorfer and Milward 1993; Duncan and Holland 2006). If newborn sharks inhabit areas where food is limited or unavailable, maternally supplied resources may become even more essential for survival.

The Scalloped Hammerhead (Sphyrna lewini) is a cosmopolitan species found in tropical and subtropical waters throughout the world. Several nursery areas have been identified in the United States along the Atlantic Coast, including Bulls Bay, South Carolina (Castro 1993), Cape Canaveral, Florida (Adams and Paperno 2007), and the Tolomato River, Florida (J. Gelsleichter pers comm), although parturition locations are unknown. Mature female $S$. lewini have not been captured in Bulls Bay (Castro 1993; Ulrich et al. 2007) and near-term pregnant females in Florida have been captured in offshore waters. Thus, neonatal sharks may rely on maternally provided resources until they arrive at nursery grounds and/or commence efficient feeding.

Quantifying the importance of maternal investment for $S$. lewini is complicated off the US Atlantic Coast by the presence of a cryptic species, the Carolina Hammerhead (Sphyrna gilberti; Quattro et al. 2013). While these two species are indistinguishable by external morphometric features, species-specific life history characteristics are unknown and may differ leading to potential differences in survivorship during early-life stages. Traits such as length-at-maturity, maternal condition, litter number and/or length-at-birth may affect the amount of resources mothers are able to invest in individual embryos, which in turn may influence how much of a head start newborns begin with in early life. While no information about the reproductive biology of $S$. gilberti is available, maternal investment inferences made by assessing various metrics of condition in neonatal S. lewini and S. gilberti may provide insight into differences in early-life history and reproductive strategies between these species. Therefore, the objective of this study was to examine several condition metrics (i.e., liver lipid content, hepatosomatic index, relative prey mass in stomachs) in three developmental stages of young-of-year hammerhead sharks to assess reliance on and utilization of maternal and nursery resources for the two species over the first few months of life.

\section{Methods}

\section{Sample collection}

Sharks were collected by multiple fisheries surveys conducted from 2014-2020: the South Carolina Department of Natural Resources Turtle Trawl, Cooperative Atlantic States Shark Pupping and Nursery Survey (COASTSPAN) participants, Kennedy Space Center Ecological Monitoring Program (KSCEMP), Southeast Area Monitoring and Assessment Program (SEAMAP), and the Florida Fish and Wildlife Research Institute's Fisheries-Independent Monitoring (FIM) program. Additional samples were acquired from Georgia Southern University as a result of incidental mortalities incurred through commercial shrimp trawling. The majority of samples were collected from Bulls Bay, South Carolina (33.0109 N, 79.4879 W), followed by Cape Canaveral, Florida (28.4195 N, 80.5635 W; Fig. 1). Sampling generally took place in nearshore waters $(<300 \mathrm{~m}$ from shore for Bulls Bay and $<5000 \mathrm{~m}$ for Cape Canaveral) along the open coastline at each respective site. Bulls Bay is a shallow $(0-3 \mathrm{~m})$ tidal estuarine system surrounded by extensive Sporobolus spp salt marsh flats with a bottom primarily composed of mud with shell bars and rakes. In the Cape Canaveral area, sharks were sampled along the Southeast Shoal, which is composed of sand-shell substrate divided 
A

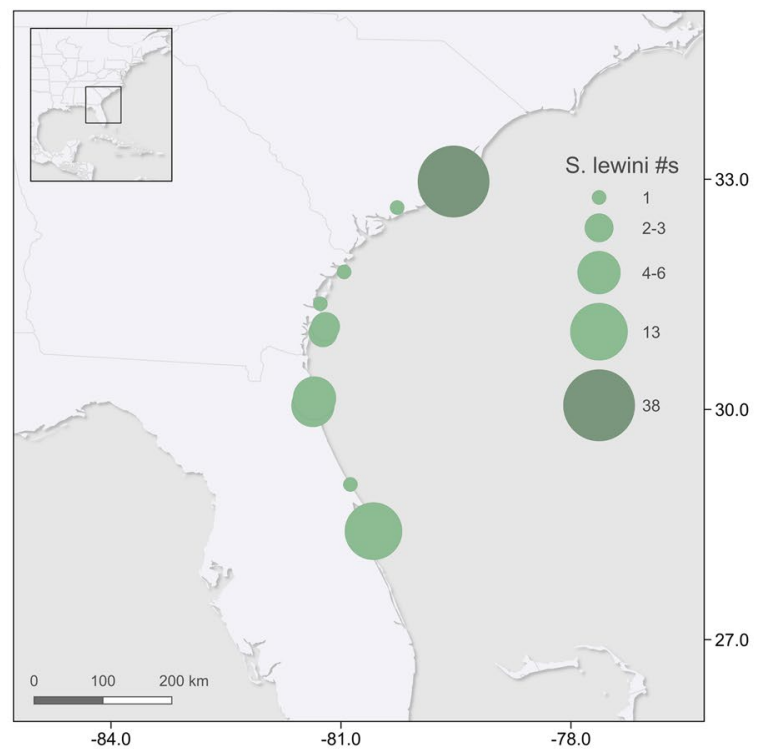

B

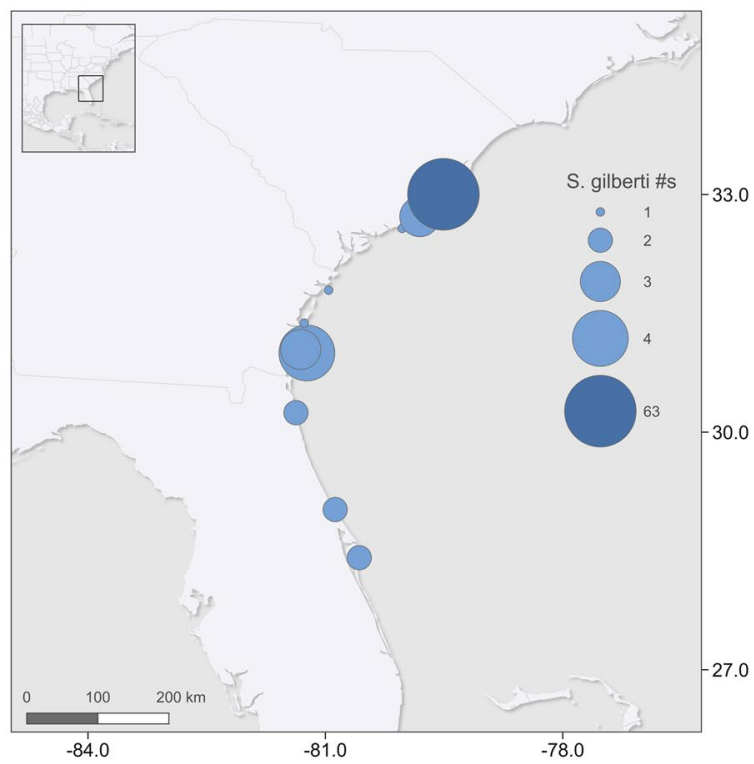

Fig. 1 Sampling locations of Scalloped Hammerhead Sphyrna lewini (a, green dots) and Carolina Hammerhead S. gilberti (b, blue dots) for samples with associated condition information along with morphometrics. Dots are proportionally sized relative to the number of samples collected in an area, except for Bulls Bay (darker colors) where a majority of samples were collected for both species

into a shallow (1-5 m depth) and deep (6-10 $\mathrm{m}$ depth) portion, and the sheltered Canaveral Bight, where sharks were most often found, which is characterized by turbid water, fine sediments, and high salinity similar to Bulls Bay. Gears used for collection of YOY hammerheads included gillnets, longlines, haul seines, and otter trawls.

Mortalities encountered during sampling operations were placed on ice and brought back to the lab where morphometric information (fork length, total body mass, liver mass, and total prey mass) were collected. Condition indices examined here included liver lipid content, relative liver mass, and consumed relative prey mass. For liver lipid content quantification, a subsample of liver $(\sim 1 \mathrm{~g})$ was extracted in a $100 \%$ dichloromethane solvent using a Soxhlet extraction apparatus for $12 \mathrm{~h}$. After extraction, solvent was removed using a rotary evaporator until the sample was $\sim 1 \mathrm{~mL}$ in volume. Concentrated extracts were then divided into two, one fraction was cleaned-up for organic contaminant analysis (Lyons, unpubl. data) and the other placed into a preweighed vial and dried at room temperature until solvent had evaporated. Lipid content was determined gravimetrically on a $\mathrm{g}$ lipid per g liver (wet mass) basis. Hepatosomatic index (HSI) was calculated as the ratio of total liver mass (g) per total body mass (g). Intact stomachs were removed whole and frozen for subsequent stomach content analysis, where prey items were then removed and weighed to obtain total prey mass. Relative prey mass was calculated as the ratio between stomach prey mass ( $\mathrm{g}$ ) and total body mass. Details on stomach prey content composition and trophic ecology (Galloway, unpubl. data) were beyond the scope of this study, and thus not reported here. Since S. lewini and $S$. gilberti are a cryptic species pair, fin clips were taken from every animal and preserved in a dimethyl sulfoxide solution for subsequent species genetic identification following the protocols of Barker et al. (2019). Hybrid individuals and those with indeterminant genetic discrimination where liver samples were taken for lipid extraction were removed from the data set $(n=14$; Supplemental Table 1).

Sphyrna lewini length-at-birth is believed to range from 248-430 mm fork length (Castro 1983; Branstetter 1987; Stevens and Lyle 1989; Chen et al. 1990; White et al. 2008; Amorim et al. 2011), making it difficult to use this parameter to determine time-since-birth of any one individual, especially since previously published length estimates from studies in the US Atlantic likely included S. gilberti. Thus, umbilical scar healing information was used as a proxy of time since birth as employed in other studies (Hussey et al. 2010; Olin et al. 2014). When data were available, sharks were ranked based on the degree of healing similar to the methods outlined by Duncan and Holland (2006). Sharks with umbilical tissue remaining or freshly open scars without evidence of healing were given a scar rank of 0 , those with partial healing a rank of 1 , mostly healed scars a rank of 2 , well healed scars a rank of 3 , and fully healed scars assigned a rank of 4 . For reference, it takes approximately 2 weeks for S. lewini to transition from open to healed scars in a semi-controlled environment (Duncan and Holland 2006). While the possibility exists that abiotic (e.g., temperature) or biotic factors (e.g., stress) may affect how quickly scars heal or its variability among individuals, scar healing stage likely represents the best available proxy for time-since-birth. Given the low sample availability of neonates (scar rank $0-2$ ), YOY sharks were subsequently grouped into broader 
categories reflecting approximate time since birth for data analysis: neonatal, mid-stage (scar rank 3), and late-stage (scar rank 4).

Since parturition locations are unknown, obtaining samples of sharks immediately after birth to determine "starting" condition was not possible; therefore, condition data available from two near-term litters of $S$. lewini embryos (Lyons and Adams 2015) were used as "at birth" reference points. Gravid females were assumed to be S. lewini as they were caught off Florida's Atlantic coast near Miami in 2006 and 2009 using hook and line gear. Very little is known about the distribution or movements of $S$. gilberti. Attempts to sample near-term pregnant $S$. gilberti via longlining were unsuccessful despite broad sampling efforts, highlighting the need for further studies to characterize the basic biological aspects of this species. Therefore, S. lewini embryos were used as a reference point for both species.

\section{Data analysis}

\section{Early-life resource utilization}

Liver lipid content, HSI, and consumed relative prey mass condition indices were compared between species for neonatal and mid-stage YOY and across fork length (all scar stages, see paragraph below). Late-stage YOY were excluded since time since birth was impossible to gauge as their scars were fully healed. Condition indices were compared between species and stages (neonatal or mid-stage) using bootstrapped $t$-tests $(n=1000)$ with resampling and sample sizes equal to the group with the lowest number of individuals. Resulting $p$ values were Bonferroni-corrected and the median $p$ value, $\max p$ value and percent of occurrences with significance were examined to determine if differences among groups existed. Group summaries are reported as mean \pm standard deviation unless otherwise specified. Significance level $(\alpha)$ was set to 0.05 and 0.008 for non-bootstrapped and bootstrapped analyses, respectively.

The relationship of condition metrics to fork length was also determined by scar stage within species through linear regressions. The effect of species on condition indices was explored through ANCOVA and included scar stage as a main factor when appropriate (i.e., when data from different stages could not be combined). When normality of residuals deviated, values were $\log _{10}$ transformed prior to analyses. Total body mass-fork length and liver mass-fork length relationships were also quantified by species and stage. Parameters for allometric relationships $\left(M=\mathrm{a} L^{\mathrm{b}}\right)$ were obtained using the formula $\log (M)=\log (\mathrm{a})+\mathrm{b} \log (L)$, where $\mathrm{M}$ was either total body mass or liver mass, $L$ was fork length, and a and $\mathrm{b}$ represent the $y$-intercept and slope, respectively. Mass-fork length relationships were compared between species using an ANCOVA. Year was not included as a factor since sample sizes were not consistent across years. Similarly, location was not included because most samples from this dataset were from South Carolina.

\section{Growth dynamics across nurseries}

Temporal and geographical growth patterns in YOY were explored using a larger data set from Barker et al. (2019). Since this data set did not include scar healing or condition information, only date of sampling, fork length, location and species identification information were used. Only fork length data were used for this analysis as it tends to be more accurate than mass when taken in the field across collaborative groups. Sampling date was converted into a temporal metric "day-of-year" (DOY) and both DOY and fork length were $\log _{10}$-transformed. The effect of DOY and coastal region by state on species fork length was tested using ANCOVA, including interactions.

\section{Results}

\section{Sample distribution}

A total of 154 samples with associated condition information were collected from the two species, with the majority of individuals $(\sim 70 \%)$ caught off South Carolina $(n=107)$, followed by Florida $(\sim 20 \%, n=31)$, and Georgia $(\sim 10 \%$, $n=16$; Fig. 1). Neonates were the least numerous category for each species, followed by mid-stage for $S$. gilberti and late-stage for $S$. lewini (Table 1). The first occurrence of sharks with open scars (rank 0) was April for S. lewini and May for S. gilberti (Table 1). The relationship between fork length and scar stage for these hammerhead species was not straightforward as there was substantial overlap in fork length and date among the three scar stages (Supplemental Fig. 1), likely related to existing variation in birth length, timing of parturition, and/or individual variation in growth. Even among littermates, there was a reasonable amount of length variability for the shortest and longest embryos (min-max: litter 1=314-363 mm FL, litter 2=292-352 mm FL), indicating that fork length at parturition differs within litters. Furthermore, when comparing embryos to freeswimming YOY, $10 \%$ of late-stage $S$. lewini YOY were still smaller than the longest near-term embryo in this study, highlighting that length alone may not be the most sensitive indicator of time-since-birth for this particular study. Thus, we chose to use scar stage as the best proxy available for time-since-birth. 


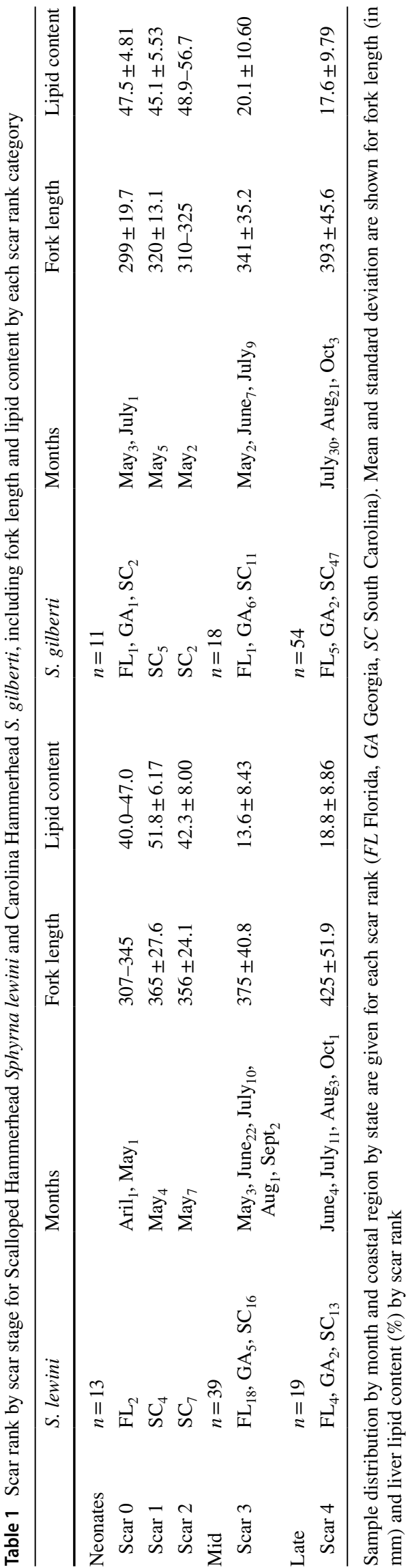

Species-specific difference in length-at-birth, as purported by Quattro et al. (2013), was supported in this study. Among late-stage $S$. gilberti YOY, $35 \%$ were smaller than the largest $S$. lewini embryo, suggesting S. gilberti are born as smaller lengths. In addition, no neonatal $S$. gilberti $(0 / 11)$ were larger than the largest near-term $S$. lewini embryo (363 mm fork length), whereas half (6/13) neonatal S. lewini were larger (Supplemental Fig. 1). By contrast, two neonatal and two mid-stage $S$. gilberti were smaller than the smallest S. lewini embryo (293 mm fork length), while the smallest free-swimming S. lewini in this data set was $307 \mathrm{~mm}$ fork length.

\section{Condition metrics}

Liver lipid content in neonatal S. lewini $(45.4 \pm 7.95 \%)$ and $S$. gilberti $(47.4 \pm 5.55 \%)$ were similar to late-term embryos $(45 \pm 5 \%)$. However, mean lipid content significantly fell from neonatal to mid-stage in both $S$. lewini (bootstrap $t$-test, largest $P<0.0001$ ) and $S$. gilberti $(P<0.0009$; Fig. 2$)$, with no significant differences between species for comparable stages (Supplemental Fig. 2). During this time, YOY mean lipid content decreased by $70 \%$ in S. lewini and $58 \%$ in S. gilberti, but lipid content appeared to rebound in late-stage YOY, as they were the only stage to show significant increases in lipid content with fork length (linear regression, $\mathrm{LN}$ transformed; S. lewini: $F_{1,17}=16.07, r^{2}=0.46, P=0.0009$; S. gilberti: $\left.F_{1,52}=37.7, r^{2}=0.41, P<0.0001\right)$, with no significant differences between species (ANCOVA, $F_{1,69}=0.78, P=0.3$; Fig. 3). Only the largest late-stage YOY ( $>500 \mathrm{~mm}$ fork length) sampled late in the year

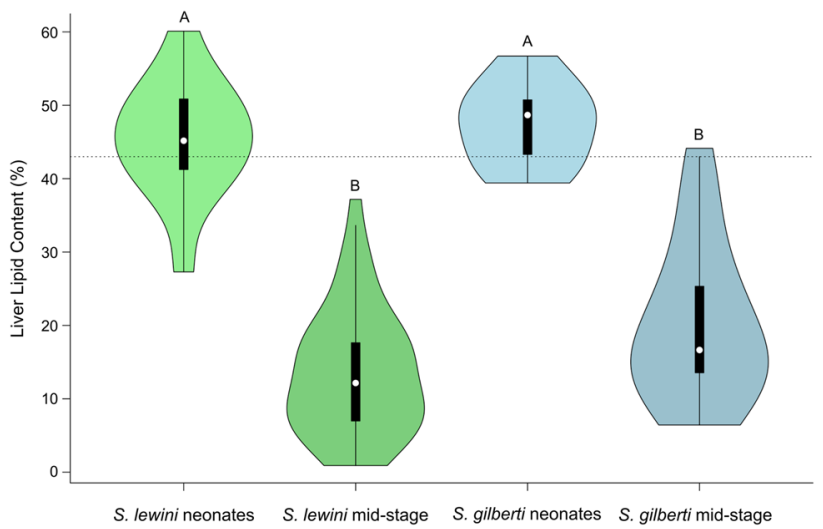

Fig. 2 Relative liver lipid content (\%) for neonatal and mid-scar stage Scalloped Hammerhead Sphyrna lewini (green, left side) and Carolina Hammerhead S. gilberti (blue, right side). Different letters indicate significant differences based on comparative bootstrap $t$-tests ( $\alpha=0.008$; see supplemental for details). Mean near-term $S$. lewini embryo liver lipid content is shown as a dashed horizontal line for reference 
(October) for both species had liver lipids that were comparable to values measured in embryos.

Species-specific differences between stages were more apparent for HSI condition. Within species, neonates had significantly heavier livers relative to their body mass compared to mid-stage YOY for S. lewini (bootstrap $t$-test, largest $P$ value $=0.0014)$ and $S$. gilberti $(P=0.0045$; Fig. 4). However, neonatal $S$. gilberti were more likely to have relatively heavier livers compared to neonatal $S$. lewini (i.e., 808/1000 with $P<0.008$, median $P=0.0011$; Supplemental Fig. 3). As such, mean HSI values across embryos $(6.89 \pm 1.77)$ were closer to neonatal $S$. gilberti $(7.14 \pm 1.46)$ than corresponding individuals from their own species $(5.08 \pm 1.07)$. Possibly as a consequence of heavier livers early in life, mid-stage $S$. gilberti were
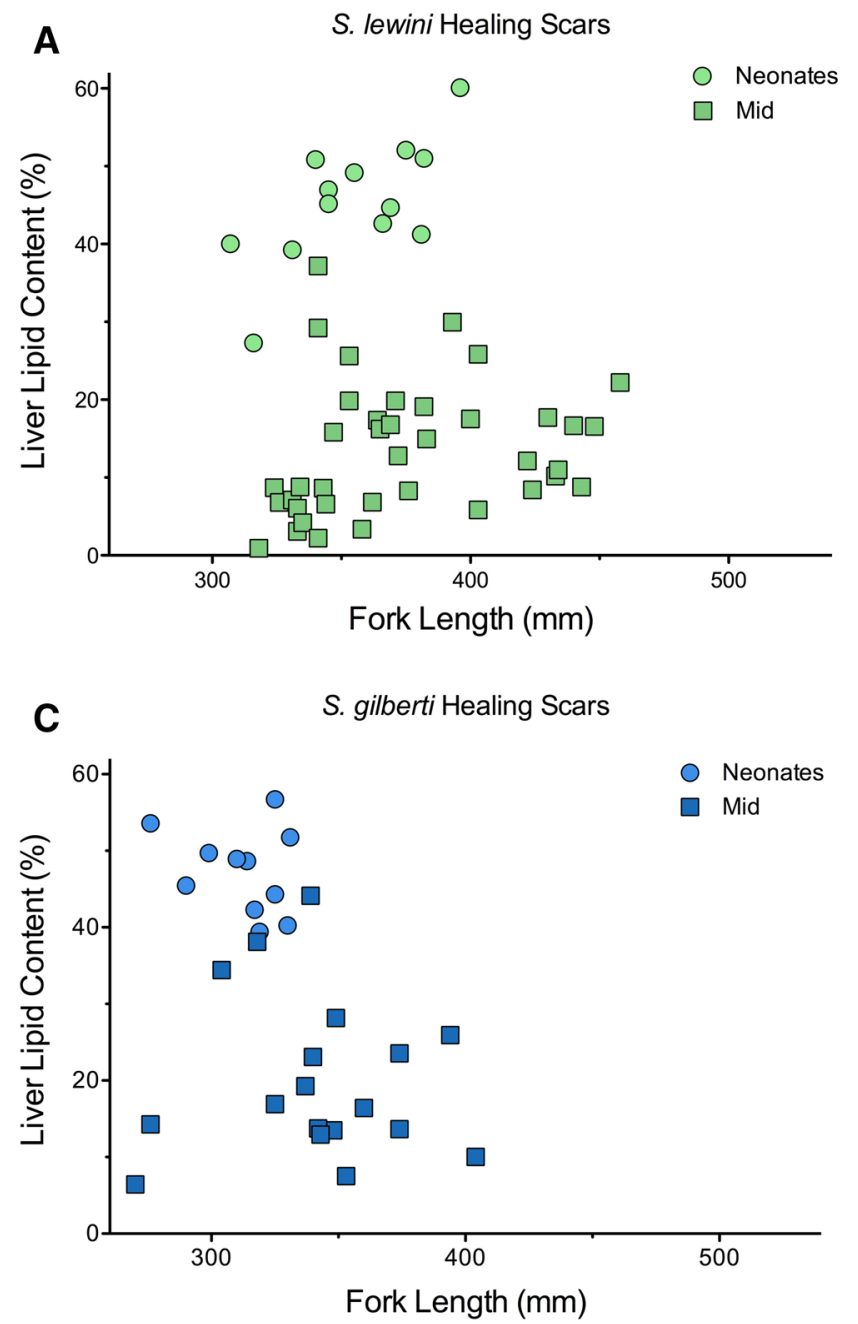

Fig. 3 Relative liver lipid content (\%) for Scalloped Hammerhead Sphyran lewini (A, B) and Carolina Hammerhead S. gilberti (C, D) across fork length. Neonatal (circles) and mid (squares) scar stages are shown in the left-hand panels and late scar stages (triangles) are more likely to have higher HSI than mid-stage $S$. lewini (i.e., 972/1000 with $P<0.008$, median $P=0.0002$ ). Hepatosomatic index significantly increased with fork length for late-stage $S$. gilberti $\left(F_{1,52}=13.86, r^{2}=0.20\right.$, $P=0.0005)$ and similarly between mid- and late-stage $S$. lewini $\left(F_{1,56}=16.28, r^{2}=0.21, P=0.0002\right.$, stages combined). However, HSI values were significantly higher in late-stage $S$. gilberti (i.e., elevated y-intercept, ANCOVA, $\left.F_{1,108}=18.45 P<0.0001\right)$ than for mid-and late-stage $S$. lewini combined.

Most individuals $(96 \%, 148 / 154)$ had prey present in their stomachs. Among neonatal S. gilberti, scar rank 0 had the highest occurrence of empty stomachs $(50 \%, 2 / 4)$ followed by scar rank $1(20 \%, 1 / 5)$ with no empty stomachs in scar rank $2(0 \%, 0 / 2)$. By contrast, neonatal $S$.
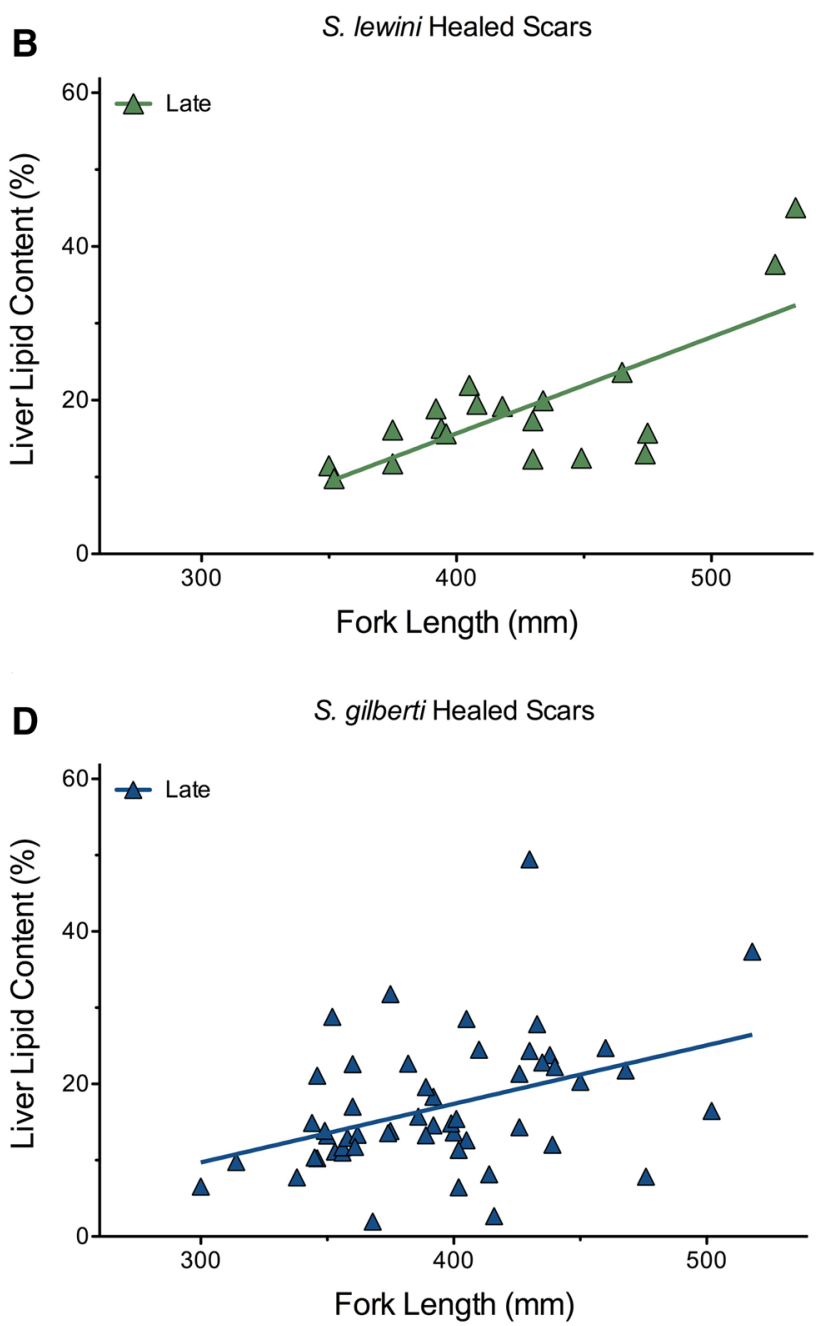

shown in the right-hand panels. Solid lines indicate significant relationships between fork length and lipid content (LN-transformed; $S$. lewini: $F_{1,17}=16.07, r^{2}=0.46, P=0.0009 ;$ S. gilberti: $F_{1,52}=37.7$, $\left.r^{2}=0.41, P<0.0001\right)$ 


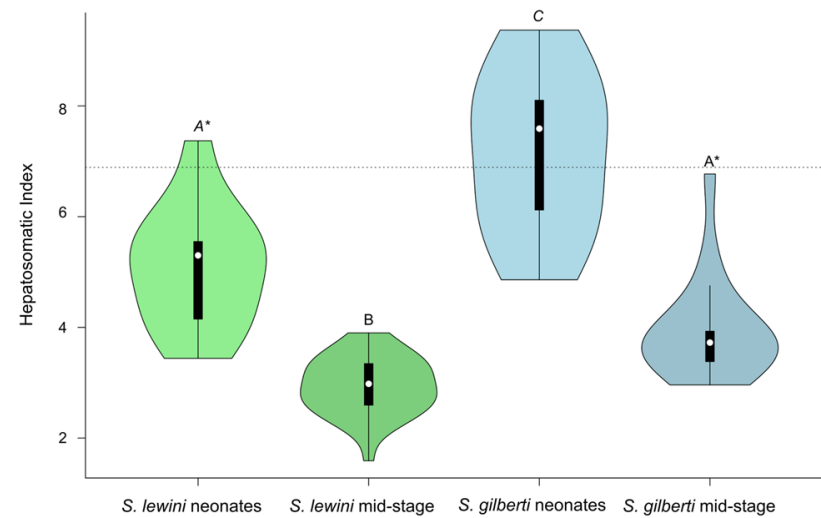

Fig. 4 Hepatosomatic index (HSI) for neonatal and mid-scar stage Scalloped Hammerhead Sphyrna lewini (green, left side) and Carolina Hammerhead S. gilberti (blue, right side). Different letters indicate significant differences based on comparative bootstrap $t$-tests $(\alpha=0.008$; see supplemental for details). Groups sharing italicized letters indicate they were significantly different 808 out of 1000 bootstrap $t$-tests $(\sim 80 \%)$, while groups sharing asterisks indicate groups were significantly different 576 out of 1000 bootstrapped $t$-tests $(\sim 58 \%)$. Mean near-term embryo HSI is shown as a dashed horizontal line for reference

lewini had low rates of empty stomachs $(7.7 \%, 1 / 13)$, with the single individual having an empty stomach of scar rank 2. Among mid- and late-stage YOY, nearly every individual had prey in their stomachs $(98 \%, 128 / 130$ species combined). Relative prey mass (amount of prey consumed per body mass) was not different between species or scar stages ( $p$ values were significant for $\geq 97.4 \%$ of bootstrap trials; Supplemental Fig. 4). In addition, relative prey stomach content mass had no association with liver lipid content or HSI for either species (all $P \geq 0.2$ ).

\section{Allometric relationships}

Total body mass increased in an exponential fashion as a factor of fork length in both $S$. lewini and $S$. gilberti YOY, with no differences among scar stages within species (ANCOVA, $P \geq 0.3$; Fig. 5). However, when comparing allometric relationships between species, S. lewini had significantly higher rates of body mass increase per fork length (i.e., steeper slope) than S. gilberti (ANCOVA, $\left.F_{1,150}=8.98, P=0.003\right)$. Liver mass increase with respect to fork length was more complicated among scar stages and between species (Fig. 5; Supplemental Table 2). For $S$. gilberti, scar stage had a significant effect such that y-intercepts were significantly different among them (ANCOVA, $\left.F_{2,77}=49.4, P<0.0001\right)$, although mass increase per fork length (i.e., slopes) were similar $(P=0.4)$. As expected, neonates had the heaviest liver masses of all stages (i.e., elevated y-intercept, $P \leq 0.0001)$, followed by mid-stage which were heavier than late-stage YOY $(P=0.003)$. While scar stage was also significant in the overall model for S. lewini (ANCOVA, $F_{2,65}=47.8, P<0.0001$ ), only neonates were heavier (i.e., elevated y-intercept) than either mid- and late-stage individuals $(P \leq 0.0001)$, which were not different from each other $(P=0.9)$. Between species, $S$. gilberti had significantly heavier livers (i.e., elevated y-intercepts $)$ at both the neonatal $\left(F_{1,20}=18.9\right.$, $P=0.0003)$ and late-stages $\left(F_{1,108}=5.86, P=0.017\right)$ when respectively compared to neonatal and combined mid- and late-stage S. lewini.

\section{Growth dynamics across nurseries}

Using a larger data set from Barker et al. (2019), the effect of time (DOY) and coastal region on growth dynamics for each species were tested (Supplemental Table 3). Both $S$. lewini $(n=128)$ and S. gilberti $(n=146)$ experienced an initial lag from time of first appearance ( DOY 115), where fork length did not show appreciable increases with time until around end of June ( DOY 175). Nevertheless, at any given point in time $S$. lewini were longer than $S$. gilberti (i.e., elevated y-intercept, $F_{1,265}=166, P<0.0001$ ), further supporting the hypothesis that $S$. lewini are born at greater lengths (Fig. 6). Coastal region also had a significant effect on fork length $\left(F_{2,265}=25.03, P<0.0001\right)$, with similar patterns between species (Fig. 6). In each case, animals sampled in Florida tended to have smaller fork lengths for comparable time points (i.e., DOY) than those sampled from South Carolina $(P=0.0008)$, despite similar timing of appearance of YOY in fisheries surveys between sites. In contrast, fork lengths were similar across time for Georgia and South Carolina $(P=0.7)$.

\section{Discussion}

Neonatal hammerhead sharks appear to heavily rely on maternally provided resources in early life, highlighted by the dramatic drop in liver lipid content and decrease in relative liver mass in sharks with open and partially healed scars. Because young sharks quickly exhaust endogenous resources provided in utero, it is likely that maternal provisioning plays a crucial role in the survivorship during the first weeks after birth. Thus, this study lends support for the maternal head start hypothesis (Berkeley et al. 2004; Donelson et al. 2008; Hussey et al. 2010) and highlights the importance of maternal investment as part of the life history strategy of these animals.

Factors related to hammerhead ecology or physiology could account for the significant drop in condition during early life. The high metabolic rate (Lowe 2001, 2002) and energetic requirements (Duncan 2006) of YOY S. lewini, 


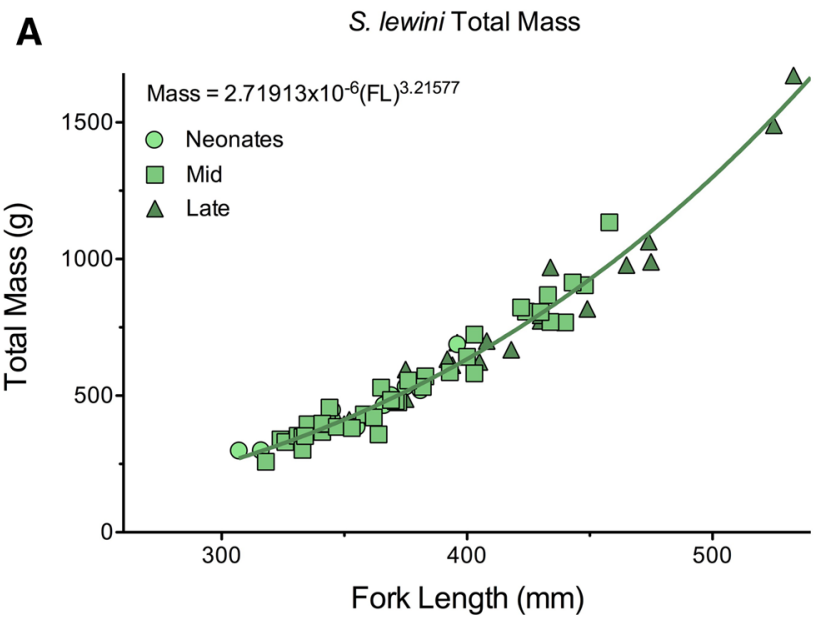

C

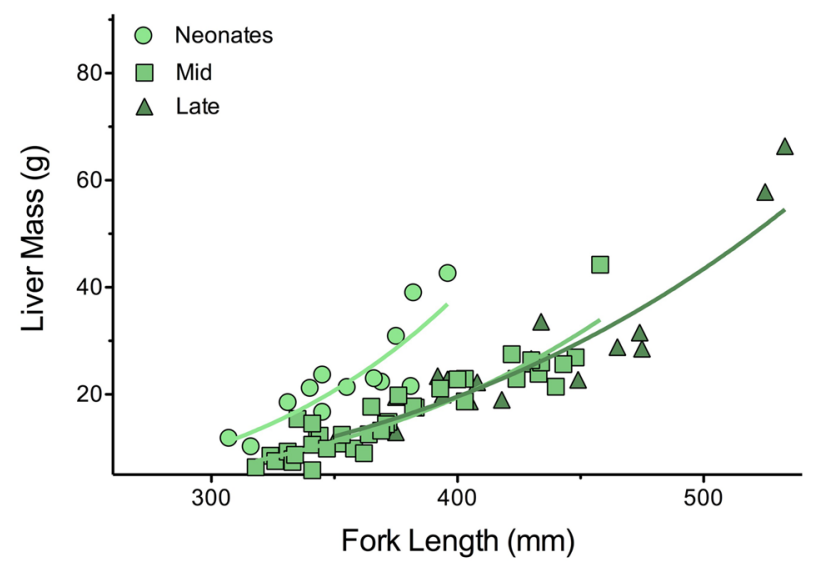

Fig. 5 Scaling of total mass (a, b) and liver mass (c, d) against fork length for Scalloped Hammerhead Sphryna lewini (a, c) and Carolina Hammerhead $S$. gilberti (b, d). Scar stages are shown in light to dark shades for neonatal (circles), mid-stage (squares) and late-stage (triangles). For total mass allometry, no differences were found amongst stages and solid lines represent the relationship with all stages com-

coupled with a poor ability to feed or low nursery quality, in terms of prey availability, could lead to a scenario where sharks are unable to meet their caloric needs. While stomach content analysis only represents a snapshot in time, most samples had prey present in their stomachs, suggesting both species were successful at exogenous feeding from an early age. An alternative explanation for the rapid drop in condition during the first weeks of life could be related to species life history and where females choose to give birth. For instance, it may be that pups are born outside the nursery grounds and migrate in from the site of parturition. Since scars would have begun healing during the migration, YOY would present with partially healed scars by the time they arrive at the nursery. This could account for the lower occurrence of sharks with fully open scars (ranks 0-2) as

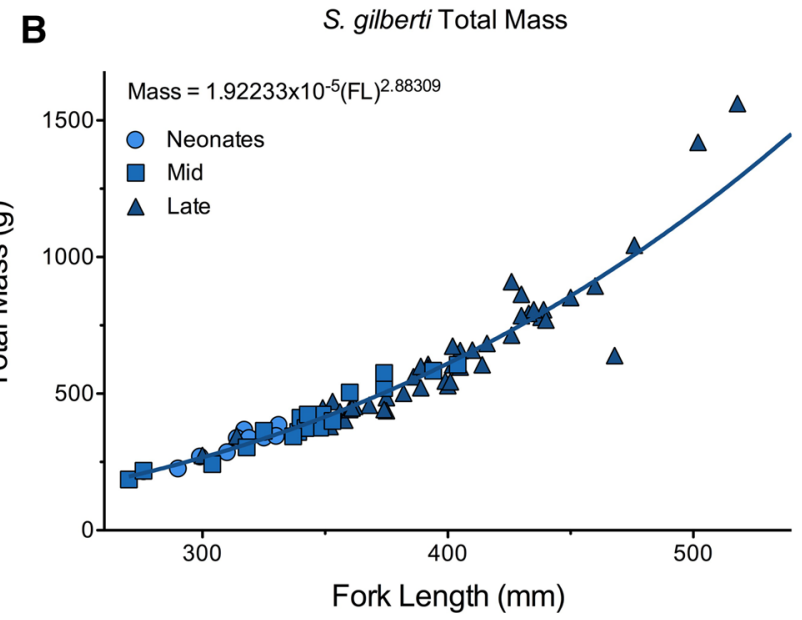

D

S. lewini Liver Mass

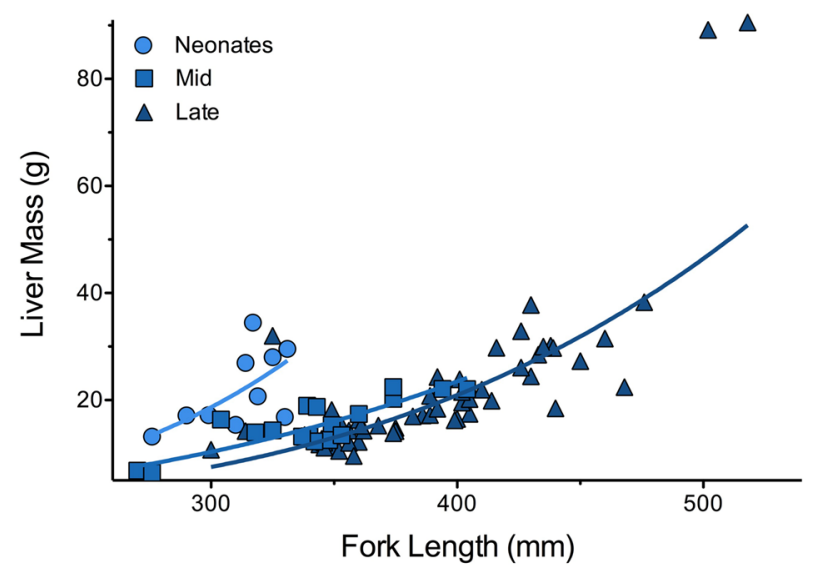

bined, with species equations in the top, left corners of the panels. Allometry relationships for liver mass were not similar among stages (except for mid- and late-stage S. lewini) and relationships for each stage are shown in their corresponding colors (see supplemental for allometry equations)

well as the higher abundance of YOY with partially healed scars (rank 3 ) in this data set. It follows that neonates would be exclusively relying on endogenous energetic stores during this time, which may explain the rather rapid decline in early-life condition. The period from birth to establishment in a nursery is likely challenging for newborn animals. As such, the drop in condition observed in neonatal hammerheads could also be related to stressors associated with living independently of their mother, which may exacerbate energy loss. The rapid decline in neonatal condition may indicate that hammerheads are particularly sensitive to perturbations, which has conservation implications for early-life survivorship.

As a consequence of exhausting their maternally provided resources, neonatal hammerheads may need to begin feeding 

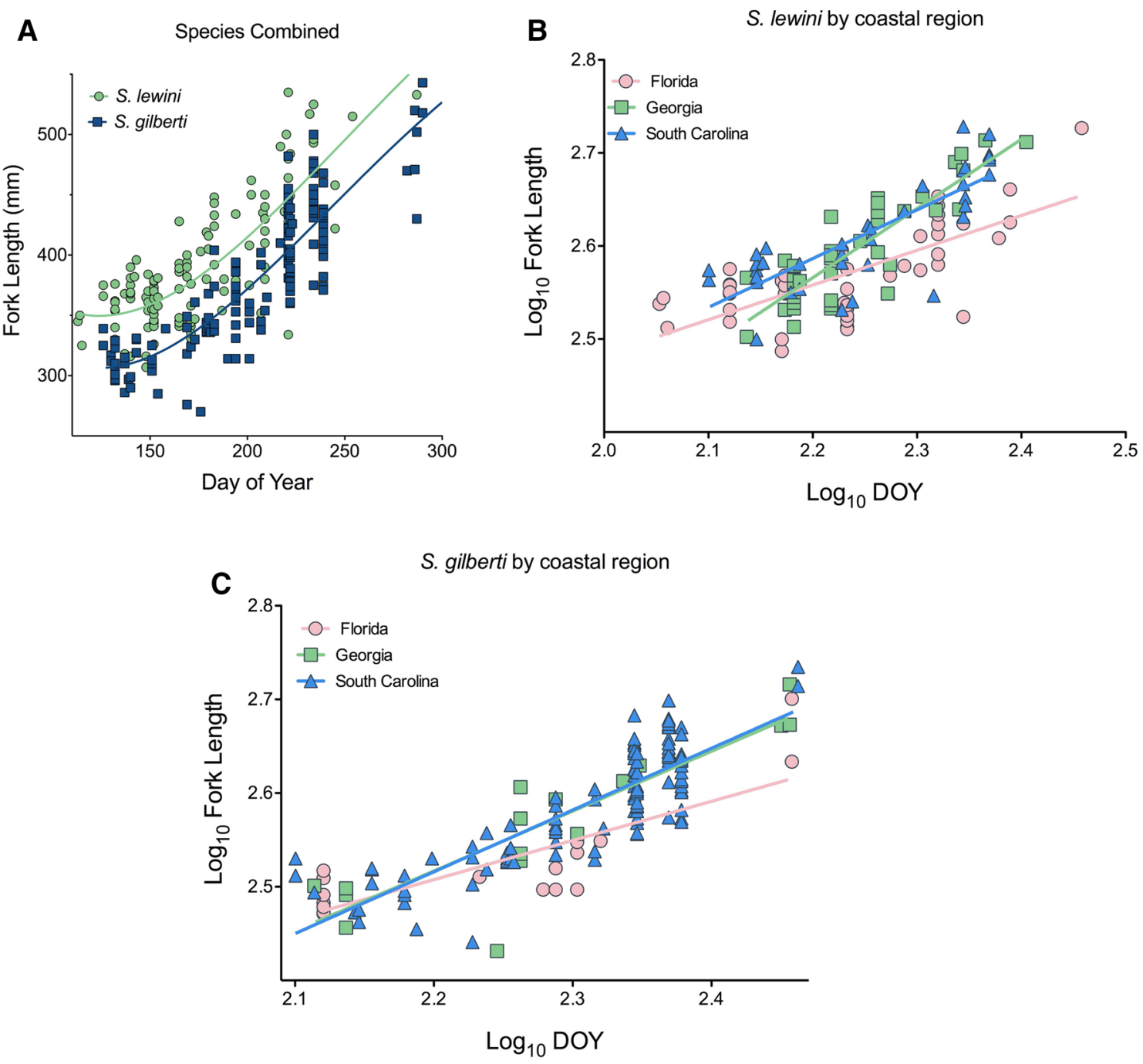

Fig. 6 Fork length and day-of-year (DOY) sampling information from Barker et al. (2019) comparing species (a) as well as by coastal region for Scalloped Hammerhead Sphryna lewini (b) and Carolina Hammerhead S. gilberti (c). Note that panels $\mathbf{b}$ and $\mathbf{c}$ display

immediately. In the current study, 96\% of YOY hammerhead stomachs had prey items, which is higher than other co-occurring YOY species. For comparison, in the Gulf of Mexico, only $63 \%$ of YOY Atlantic Sharpnose Shark (Rhizoprionodon terraenovae) and $76 \%$ of YOY Blacktip Shark (Carcharhinus limbatus) stomachs contained prey items (Bethea et al. 2004). The high occurrence of hammerhead stomachs with prey items is not unique to the Atlantic; $85 \%$ of YOY and juveniles from southeastern Gulf of California (Torres-Rojas et al. 2010) and 94.9\% of YOY from northwest Florida (Bethea et al. 2011) contained prey items in their stomachs. In addition to feeding often, YOY hammerheads may also need to feed indiscriminately. For instance, a large number of prey items have been identified in the stomachs of both S. lewini $(\sim 43)$ and S. gilberti $(\sim 34)$ $\log _{10}$-transformed data. Significant relationships $(\alpha=0.05)$ are shown in solid lines. Coastal regions are grouped by state: $S C$ South Carolina, GA Georgia, FL Florida

YOY (Galloway, unpubl. data), spanning at least 13 families of teleost fishes, molluscs, and arthropods, suggesting that YOY hammerheads likely consumed whatever they were able to ingest.

If the rapid depletion of maternal reserves early in life necessitates immediate initiation of feeding, then nursery quality and function may have important implications for YOY hammerhead survivorship. With limited reserves available, neonatal hammerheads have little energetic "wiggle room" and may require reliable and rapid access to ample prey to meet their basic energetic needs. Thus, when YOY do not have access to sufficient food items, survivorship may decline. For instance, work on S. lewini YOY in Hawaii suggest that this nursery primarily functions to protect YOY from predation as body condition of these individuals are relatively 
poor (Bush and Holland 2002; Lowe 2002; Bush 2003). The Kane'ohe Bay nursery is believed to not provide adequate prey resources for YOY, so sharks using this area run the risk of starvation at the cost of protection. In particular, Kane'ohe Bay sharks with open umbilical scars had lower occurrences of prey in stomachs (41\%) compared to those with healed scars ( 88\%; Bush 2003), while in the present study $67 \%$ of sharks with open scars (rank 0) had food present in their stomachs. Furthermore, median relative prey mass was approximately three times higher in the present study for sharks with healed scars ( 0.61\%) than Kane'ohe Bay YOY $(0.22 \%$; Bush 2003), supporting previous conclusions of sub-optimal foraging for S. lewini YOY in Kane'ohe Bay.

Variation across nurseries, with respect to food quantity and quality, could have downstream implications if it translates to differences in growth or survival. While not conclusive, it was interesting that YOY sampled from Florida nurseries appeared to have potentially lower growth rates, a pattern which was consistent between species. This may be indicative of reduced prey availability or quality for the Florida coastal region as was reported for juvenile Lemon Shark (Negaprion brevirostris) caught near Cape Canaveral that had a high rate of empty stomachs and declining body condition $\left(\mathrm{g} / \mathrm{cm}^{3}\right)$ during the fall and winter (Reyier et al. 2008). Thus, while YOY hammerheads were sampled from locations in the Cape Canaveral region with the highest prey biomass (E. Reyier pers comm), that prey biomass may still be lower compared to more northern locations. Directed studies would be needed to fully quantify the differences in nursery quality along the Atlantic Coast, which has implications for not only juvenile hammerheads, but a number of other shark species as well (Castro 1993; Ulrich et al. 2007). Thus, while preliminary, these results suggest further investigation is required, as nurseries play a critical role for S. lewini and S. gilberti (Castro 1993; Simpfendorfer and Milward 1993; Maria Torres-Huerta et al. 2008), and appropriate management of essential habitat will be necessary to ensure protection for these sensitive species, especially during critical early-life periods.

While nursery quality may account for differences in growth rate, these three nurseries also occurred along a latitudinal gradient, implicating alternative mechanisms. In another sphyrnid, the Bonnethead (Sphyrna tiburo), latitudinal gradations in growth rate have also been observed, such that individuals from the northern areas grew faster and achieved larger size than their more southern counterparts (Lombardi-Carlson et al. 2003). In addition, genetic differences amongst $S$. tiburo also exist along the same latitudinal gradient (Portnoy et al. 2015). Thus, other factors besides nursery quality, could account for hammerhead growth differences across sites and future research should investigate how early-life growth trajectories may influence adult characteristics later in life.
Despite the initial drop in liver lipid content, late stage YOY appear to be able to restore liver condition, both in terms of mass and lipid content. However, the significant decrease in hepatic resources early in life may have implications for growth dynamics during the first few weeks after birth. In other words, growth may be hampered until YOY hammerheads have recouped a substantial portion of their early energy losses. For example, a temporal delay in fork length increase was observed when comparing size to sampling date (DOY). It is possible that YOY may only begin to invest energy into appreciable growth once some degree of condition has been recovered. Alternatively, this delay in growth could be reflective of protracted birth windows and variation in birth sizes, which may otherwise mask early growth patterns.

Nevertheless, increases in liver lipid content in late stage YOY indicate sufficient and successful feeding as well as a rapid transition from maternally derived to exogenously obtained resources. While more interspecies comparisons should be performed, the pace at which YOY become less dependent on maternally derived resources may have implications for tissue turnover rates, which in turn can influence studies using stable isotopes and other chemical tracers (Trueman et al. 2005), but may also provide insights into the different life history strategies species employ to maximize recruitment. For example, in contrast to hammerheads, liver lipid content decreased continually and over a longer period in Bull Shark (Carcharhinus leucas) YOY (Olin et al. 2014); however, maximum measured lipid content in C. leucas YOY with open scars was $\sim 20 \%$ higher than in either hammerhead species. While this may be attributable to differences in nursery quality, availability of food resources or differences in metabolism, there is possibility that it may reflect species-specific strategies such that YOY with higher maternal investment per embryo have less pressure to initialize feeding (i.e., have larger buffers) compared to species lower maternal investment. Further investigations of how ecology and physiology influence particular life history strategies is required in chondrichthyans.

While elasmobranch females are generally regarded as investing highly in offspring, variation in maternal provisioning among species may provide insights into evolutionary trade-offs resulting in different investment strategies. Since the liver represents the energy storage organ of elasmobranchs, and plays a critical role in metabolism, much can be inferred through the condition of this organ (often measured through HSI). In the present study, the highest HSI recorded for either hammerhead species (including embryos) was half of that reported in a comparable study examining maternal provisioning in C. obscurus neonates (HSI of 9 for hammerheads vs 20 for C. obscurus, respectively; Hussey et al. 2010). Divergence in HSI could be related to speciesspecific ecological or physiological differences from nursery 
utilization or food availability to efficiency in energy utilization. Reproductive characteristics such as litter size and gestation time may also influence the degree to which females are able to invest energy resources into individual offspring. Sphyrna lewini tend to have larger litters and shorter gestations (17-21 embryos, 12 months; Hazin et al. 2001; Stevens and Lyle 1989) than C. obscurus (3-12 embryos, 2 years; Dudley et al. 2005), which could lead to lower investment per embryo that physiologically manifests in smaller livers relative to their total body mass for $S$. lewini (and likely $S$. gilberti). However, these reproductive characteristics may also be intertwined with aspects of their ecology. For instance, in species that use prey-rich nursery areas, females may be able to conserve their own resources and invest less in offspring than they would if food availability for offspring was more limited. The relatively light liver mass in YOY hammerheads, as compared to C. obscurus, may be related to the use of productive estuarine or nearshore nurseries and less reliance on maternal stores. By contrast, YOY C. obscurus may have a relatively heavier liver mass than YOY hammerheads if they use more offshore or open coastal habitats (Dudley et al. 2005; Hussey et al. 2009) where food is limited or patchy; necessitating a greater reliance on maternally provided resources. While further interspecies comparisons are needed, species ecological and physiological characteristics may influence the evolution of particular life history strategies.

Despite external morphological similarity between $S$. lewini and $S$. gilberti, significant differences in a number of YOY biological metrics suggests that reproductive physiology likely differs between species, opening the possibility that other physiological differences exist as well. While S. lewini appear to be longer at birth, S. gilberti seem to be born with higher condition (e.g., relative liver mass and lipid content). Based on the limited availability of YOY with open scars (rank 0), S. gilberti have later parturition dates (May-July) than S. lewini (April-May), which is supported by catch data as well (Barker et al. in review). Later parturition may indicate that $S$. gilberti has a physiological preference for warmer waters or may be related to ecological partitioning to reduce competition with $S$. lewini neonates through temporal separation (Barker et al. in review). In other nurseries, temporal separation is hypothesized as a mechanism to reduce nursery overlap between the Creek Whaler (Carcharhinus fitzroyensis) and three other species of Carcharhinids (Kinney 2011); although the difference in arrival time to the nursery grounds between species was greater than the present study. However, sampling bias may also influence our understanding of when these young sharks arrive at nurseries because financial and logistical limitations may restrict survey windows and surveys may not encompass the entire pupping season. Although more work is needed to fully elucidate factors that influence maternal investment per embryo, if a tradeoff exists between condition and litter number, it is possible that $S$. gilberti may have smaller, but better provisioned litters than S. lewini. While near-term pregnant $S$. gilberti were not successfully sampled, information from this study may serve as a proxy for important biological characteristics necessary to inform management of these species that likely differ in other aspects of their ecology and physiology.

Acknowledgements Authors would like to thank V. Lorenzi and R. Gossett for their assistance in the laboratory with lipid content quantification and J. Bigman for model consultation. Thanks to J. Gelsleichter (University of North Florida) and C. Bedore (Georgia Southern University, IACUC \#: I17001, GA DNR collection permit \#1000520150) for sample donation. This is contribution 832 of the South Carolina Marine Resources Center.

Funding This study was supported by grant funds from the P.E.O. Fellowship awarded to KL. SCDNR work was funded by U.S. Fish and Wildlife Service Competitive State Wildlife Grant number SC-U2-15AP00050 and15AP00050 and South Carolina State Wildlife Grant SC-T-F18AF00964. TAMU-CC work was funded by NOAA/NMFS Cooperative Research Program Grant number NA14NMF4540063 and the aforementioned Competitive State Wildlife Grant.

Data availability The datasets generated during and/or analyzed during the current study are available from the corresponding author on reasonable request.

\section{Compliance with ethical standards}

Conflict of interest The authors declare that they have no conflict of interest.

Ethical approval All sharks were sampled by authorized staff under official permits or scientific exemptions of U.S. state government agencies.

Open Access This article is licensed under a Creative Commons Attribution 4.0 International License, which permits use, sharing, adaptation, distribution and reproduction in any medium or format, as long as you give appropriate credit to the original author(s) and the source, provide a link to the Creative Commons licence, and indicate if changes were made. The images or other third party material in this article are included in the article's Creative Commons licence, unless indicated otherwise in a credit line to the material. If material is not included in the article's Creative Commons licence and your intended use is not permitted by statutory regulation or exceeds the permitted use, you will need to obtain permission directly from the copyright holder. To view a copy of this licence, visit http://creativecommons.org/licenses/by/4.0/.

\section{References}

Adams DH, Paperno R (2007) Preliminary Assessment of a Neashore Nursery Ground for the Scalloped Hammerhead off the Atlantic Coast of Florida. In: C. T. McCandless, N. E. Kohler, and H. L. Pratt J (ed) Shark nursery grounds of the Gulf of Mexico and 
the east coast waters of the United States, American Fisheries Society Symposium. Bethesda, Maryland, 165-174

Amorim AF, Della-Fina N, Piva-Silva N (2011) Hammerheads sharks, Sphyrna lewini and S. zygaena caught by longliners off Southern Brazil, 2007-2008. Collect Vol Sci Pap ICCAT 66:2121-2133

Barker AM, Adams DH, Driggers WB, Frazier BS, Portnoy DS (2019) Hybridization between sympatric hammerhead sharks in the western North Atlantic Ocean. Biol Lett 15:20190004

Berkeley SA, Chapman C, Sogard SM (2004) Maternal age as a determinant of larval growth and survival in a marine fish, Sebastes melanops. Ecology 85:1258-1264

Bethea DM, Buckel JA, Carlson JK (2004) Foraging ecology of the early life stages of four sympatric shark species. Mar Ecol Prog Ser 268:245-264

Bethea DM, Carlson JK, Hollensead LD, Papastamatiou YP, Graham BS (2011) A comparison of the foraging ecology and bioenergetics of the early life-stages of two sympatric hammerhead sharks. Bull Mar Sci 87:873-889

Branstetter S (1987) Age, growth and reproductive biology of the Silky Shark Carcharhinus falciformis and the Scalloped Hammerhead Sphyrna lewini from the Northwestern Gulf of Mexico. Environ Biol Fishes 19:161-174

Bush A (2003) Diet and diel feeding periodicity of juvenile scalloped hammerhead sharks, Sphyrna lewini, in Kane'ohe Bay, O'ahu, Hawai'i. Environ Biol Fishes 67:1-11

Bush A, Holland K (2002) Food limitation in a nursery area: estimates of daily ration in juvenile scalloped hammerheads, Sphyrna lewini (Griffith and Smith, 1834) in Kane'ohe Bay, O'ahu, Hawai'i. J Exp Mar Bio Ecol 278:157-178

Castro J (1983) The Sharks of North American Waters. Texas A\&AM University Press, College Station TX

Castro JI (1993) The shark nursery of Bulls Bay, South Carolina, with a review of the shark nurseries of the southeastern coast of the United States. Environ Biol Fishes 38:37-48

Chen CT, Leu TC, Joung SJ, Lo NCH (1990) Age and growth of the scalloped hammerhead, Sphyrna lewini, in northeastern Taiwan waters. Pac Sci 44(2): 156-170

Compagno LJ V (1990) Alternative life-history styles of cartilaginous fishes in time and space. Environ Biol Fish 28:33-75. https ://doi.org/10.1007/BF00751027

Congdon JD (1989) Proximate and evolutionary constraints on energy relations of reptiles. Physiol Zool 62:356-373

Cotton CF, Dean Grubbs R, Dyb JE, Fossen I, Musick JA (2015) Reproduction and embryonic development in two species of squaliform sharks, Centrophorus granulosus and Etmopterus princeps: Evidence of matrotrophy? Deep Sea Res Part II Top Stud Oceanogr 115:41-54

Donelson JM, McCormick MI, Munday PL (2008) Parental condition affects early life-history of a coral reef fish. J Exp Mar Bio Ecol 360:109-116

Dudley SFJ, Cliff G, Zungu MP, Smale MJ (2005) Sharks caught in the protective gill nets off KwaZulu-Natal, South Africa. 10. The dusky shark Carcharhinus obscurus (Lesueur 1818). African J Mar Sci 27:107-127

Duncan KM (2006) Estimation of daily energetic requirements in young scalloped hammerhead sharks, Sphyrna lewini. Environ Biol Fishes 76:139-149

Duncan KM, Holland KN (2006) Habitat use, growth rates and dispersal patterns of juvenile scalloped hammerhead sharks Sphyrna lewini in a nursery habitat. Mar Ecol Prog Ser 312:211-221

Guttridge TL, Myrberg AA, Porcher IF, Sims DW, Krause J (2009) The role of learning in shark behaviour. Fish Fish 10:450-469

Hamlett WC, Jones CJ, Paulesu LR (2005a) Placentatrophy in sharks. In: Hamlett W (ed) Reproductive biology and phylogeny of chondrichthyes: sharks, batoids and chimaeras. Science Publishers Inc, Enfield, NH, pp 463-502

Hamlett WC, Kormanik G, Storrie M, Stevens B, Walker TI (2005b) Chondrichthyan parity, lecithotrophy and matrotrophy. Reprod Biol Phylogeny Chondrichthyes Sharks, Batoids Chimaeras 3:394-434

Hazin F, Fischer A, Broadhurst M (2001) Aspects of reproductive biology of the Scalloped Hammerhead Shark, Sphyrna lewini, off Northeastern Brazil. Environ Biol Fishes 61:151-159

Hussey NE, McCarthy ID, Dudley SFJ, Mann BQ (2009) Nursery grounds, movement patterns and growth rates of dusky sharks, Carcharhinus obscurus: a long-term tag and release study in South African waters. Mar Freshw Res 60:571-583

Hussey NE, Wintner SP, Dudley SFJ, Cliff G, Cocks DT, Aaron MacNeil M (2010) Maternal investment and size-specific reproductive output in carcharhinid sharks. J Anim Ecol 79:184-193

Kinney MJ (2011) The communal nursery area paradigm revisited: niche overlap versus niche separation among juvenile shark species of Cleveland Bay. PhD thesis, James Cook University

Lombardi-Carlson LA, Cortés E, Parsons GR, Manire CA (2003) Latitudinal variation in life-history traits of bonnethead sharks, Sphyrna tiburo,(Carcharhiniformes: Sphyrnidae) from the eastern Gulf of Mexico. Mar Freshw Res 54:875-883

Lowe CG (2001) Metabolic rates of juvenile scalloped hammerhead sharks (Sphyrna lewini). Mar Biol 139:447-453

Lowe CG (2002) Bioenergetics of free-ranging juvenile scalloped hammerhead sharks (Sphyrna lewini) in Kane'ohe Bay, O'ahu, HI. J Exp Mar Bio Ecol 278:141-156

Lyons K, Adams DH (2015) Maternal offloading of organochlorine contaminants in the yolk-sac placental scalloped hammerhead shark (Sphyrna lewini). Ecotoxicology 24:553-562

Maria Torres-Huerta A, Villavicencio-Garayzar C, Corro-Espinosa D (2008) Reproductive biology of the scalloped hammerhead shark Sphyrna lewini Griffith \& Smith (Sphyrnidae) in the Gulf of California. Hidrobiologica 18:227-237

Musick J, Ellis J (2005) Reproductive evolution of chondrichthyans. In: W. Hamlett and B. Jamieson (Eds) Reproductive Biology and Phylogeny of Chondrichthyes: Sharks, Batoids and Chimaeras. CRC Press, Boca Raton FL, pp 45-79.

Olin JA, Beaudry M, Fisk AT, Paterson G (2014) Age-related polychlorinated biphenyl dynamics in immature bull sharks (Carcharhinus leucas). Environ Toxicol Chem 33:35-43

Portnoy DS, Puritz JB, Hollenbeck CM, Gelsleichter J, Chapman D, Gold JR (2015) Selection and sex-biased dispersal in a coastal shark: the influence of philopatry on adaptive variation. Mol Ecol 24:5877-5885

Quattro JM, Driggers WB, Grady JM, Ulrich GF, Roberts MA (2013) Sphyrna gilberti sp. nov., a new hammerhead shark (Carcharhiniformes, Sphyrnidae) from the western Atlantic Ocean. Zootaxa 3702:159-178

Reyier EA, Adams DH, Lowers RH (2008) First evidence of a high density nursery ground for the lemon shark, Negaprion brevirostris, near Cape Canaveral Florida. Florida Sci 71:134-148

Simpfendorfer CA, Milward NE (1993) Utilisation of a tropical bay as a nursery area by sharks of the families Carcharhinidae and Sphyrnidae. Environ Biol Fishes 37:337-345

Stevens JD, Lyle JM (1989) Biology of three hammerhead sharks (Eusphyra blochii, Sphyrna mokarran and S. lewini) from northern Australia. Mar Freshw Res 40:129-146

Torres-Rojas YE, Hernández-Herrera A, Galván-Magaña F, AlatorreRamírez VG (2010) Stomach content analysis of juvenile, scalloped hammerhead shark Sphyrna lewini captured off the coast of Mazatlán, Mexico. Aquat Ecol 44:301-308

Trueman CN, McGill RAR, Guyard PH (2005) The effect of growth rate on tissue-diet isotopic spacing in rapidly growing animals. 
An experimental study with Atlantic salmon (Salmo salar). Rapid Commun Mass Spectrom 19:3239-3247

Ulrich GF, Jones CM, Driggers WB, Drymon JM, Oakley D, Riley C (2007) Habitat utilization, relative abundance, and seasonality of sharks in the estuarine and nearshore waters of South Carolina. In: American Fisheries Society Symposium. 125

White WT, Bartron C, Potter IC (2008) Catch composition and reproductive biology of Sphyrna lewini (Griffith \& Smith)(Carcharhiniformes, Sphyrnidae) in Indonesian waters. J Fish Biol 72:1675-1689
Wourms JP, Grove BD, Lombardi J (1988) The maternal-embryonic relationship in viviparous fishes. In: Physiology WSH (ed) The physiology of developing fishviviparity and posthatching juveniles. Academic Press, Cambridge, pp 1-134

Publisher's Note Springer Nature remains neutral with regard to jurisdictional claims in published maps and institutional affiliations. 